
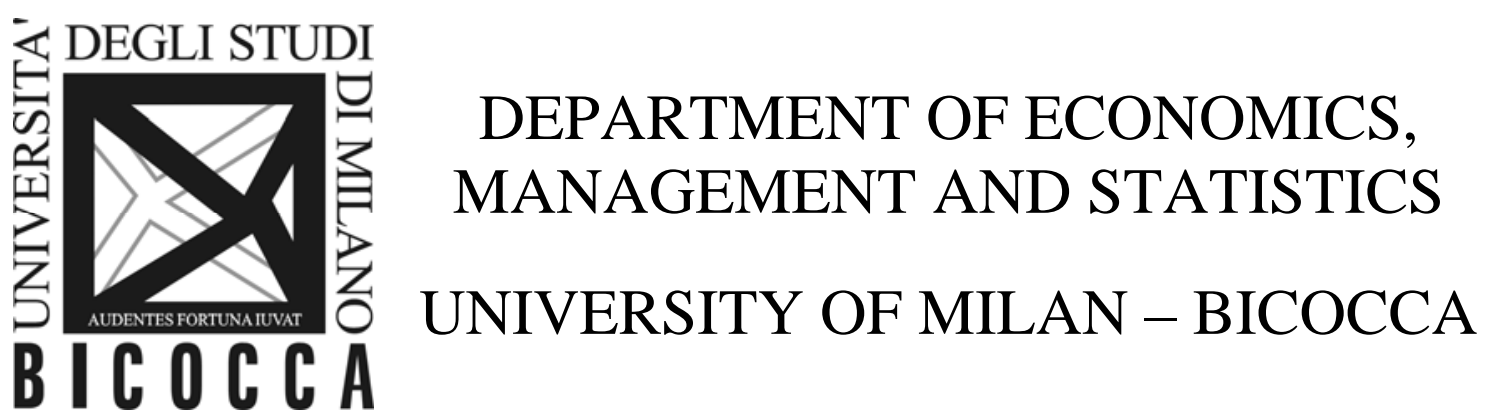

DEMS WORKING PAPER SERIES

\title{
Disinflation and Inequality in a DSGE monetary model: A Welfare Analysis
}

Maria Ferrara, Patrizio Tirelli

No. 305 - July 2015

Dipartimento di Economia, Metodi Quantitativi e Strategie di Impresa Università degli Studi di Milano - Bicocca

http://dems.unimib.it/ 


\title{
Disinflation and Inequality in a DSGE monetary model: A Welfare Analysis
}

\author{
Maria Ferrara* \\ University of Naples "Parthenope" \\ Patrizio Tirelli ${ }^{\dagger}$ \\ University of Milano-Bicocca
}

July, 2015

\begin{abstract}
We investigate the redistributive effects of a disinflation experiment in an otherwise standard medium-scale DSGE model augmented for Limited Asset Market Participation, implying that a fraction of households do not hold any wealth. We highlight two key mechanisms driving consumption and income distribution: i) the cash in advance constraint on firms working capital needs; ii) the response of profit margins to disinflation, which is crucially dependent on the two most used pricing assumptions in the New-Keynesian literature, i.e. Calvo vs Rotemberg. Results show that disinflation softens the cash in advance constraint and raises the real wage in steady state. This, in turn, lowers inequality. While under the Calvo formalism this effect is reinforced by the fall of price markups, under Rotemberg it is more than compensated by the increase of price markups and, therefore, the opposite result obtains.
\end{abstract}

JEL Classification System: E31, E5

Keywords: Disinflation, Inequality, Welfare, LAMP, Monetary Policy, Calvo Price Adjustment, Rotemberg Price Adjustment

\footnotetext{
*E-mail: ferraramaria11@gmail.com
}

${ }^{\dagger}$ E-mail: patrizio.tirelli@unimib.it 


\section{Introduction}

Recent years have witnessed increasing concern for the distributive effects of monetary policies (see the discussion in Coibion et al., 2012, and references cited therein). Empirical evidence in this regard is relatively limited and has produced partly conflicting results. Romer and Romer (1998) find that contractionary shocks increase inequality. Coibion et al. (2012) obtain identical outcomes for persistent reductions in the Fed inflation target. By the opposite, Romer and Romer (1998), Bulír (2001), Easterly and Fisher (2001) and Albanesi (2007) document a positive cross country correlation between inflation and inequality over relatively long time spans.

This paper investigates the distributional effects of disinflation in an otherwise standard medium scale DSGE model augmented for Limited Asset Market Participation (LAMP, henceforth), where it is assumed that a fraction of households (Rule of Thumb, RT hereafter) do not participate in financial markets and only consume their current labor income. As a matter of fact, the empirical evidence highlights that economies are not populated by representative agents ${ }^{1}$, so distributional issues must be taken into account. Our contribution is akin to Ascari and Ropele (2012), henceforth AR, who simulate a disinflation experiment within a standard DSGE model with omogeneous and forward-looking consumers. We depart from their paper in two aspects. First, we assume heterogeneity across households, namely LAMP, in line with the empirical analysis and with a common tradition in the literature ${ }^{2}$. Second, we simulate the disinflation policy exercise comparing the two most commonly used approaches for price and wage setting in the New-Keynesian literature ${ }^{3}$, i.e. the Calvo (1983) probability of price (wage) adjustment and the Rotemberg (1982) quadratic cost of price (wage) adjustment. As far as we know, this is the first paper analyzing income distribution and welfare effects of disinflation in a DSGE model with $\mathrm{LAMP}^{4}$.

Several papers show that Calvo and Rotemberg models imply the same dynamics up to the first order approximation ${ }^{5}$. By contrast, some other contributions are really sceptical about the identity of the two frameworks ${ }^{6}$. Ascari and Rossi (2012) show that once non linearities due to trend inflation are taken

\footnotetext{
${ }^{1}$ The presence of RT households has been detected and estimated by, among others, Campbell and Mankiw (1989), Fuhrer(2000). Moreover, Iacoviello and Pavan (2013) show that the $40 \%$ of US households hold no wealth and no debt. Similar figures are observed for the Euro area (Cowell et al., 2013).

${ }^{2}$ Earlier contributions that investigate the LAMP assumption include, among others, Galì et al. (2004, 2007), Bilbiie (2008), Colciago et al. (2008), Motta and Tirelli (2012).

${ }^{3}$ As in Ascari and Rossi (2012) in a simple sticky price model with only labor as productive factor.

${ }^{4}$ Instead, two seminal papers have initiated the debate about the welfare implications of Rotemberg vs Calvo price-setting mechanisms.

${ }^{5}$ See Rotemberg (1987), Roberts (1995), Ball (1994), Mankiw (2001).

${ }^{6}$ Kahn (2005) argues that despite both approaches imply the same reduced form New Keynesian Phillips Curve, the impact of competition on the slope of the NKPC and on the response of inflation and output to shocks differs between the two models.
} 
into account the dynamics of the two specifications are different. Similar results show up in our disinflation experiment under the two price adjustment mechanisms.

Disinflations are typically associated to short-run output contractions. Motta and Tirelli $(2012,2013)$ document the redistributive effects of monetary contractions, which unambiguosly penalize RT households who cannot smooth consumption and are constrained to consume their labor income. The key mechanism behind this result is the combination of reduced labor incomes and increased profit margins that follows a monetary contraction in the short run. Our model replicates this outcome and provides new insights on the long-run effects of disinflations.

In our model two key frictions have distributional implications and are also affected by the long-run inflation rate: firms markups and the cash-in-advance constraint on firms working capital (CIA henceforth) ${ }^{7}$. The CIA constraint implies that asset holders obtain nominal interest rate payments on the funds that firms borrow to finance their working capital needs (see Christiano et al., 2005). Disinflation lowers the long-run nominal inflation rate and has a powerful effect on labor demand. As a result we observe that in the long run both output and the real wage increase, whereas the real rental cost of physical capital remains constant. Thus a disinflation that lowers the cost of borrowing working capital unambiguously reduces inequality. Moreover, the long run effect of disinflation on profit margins depends on assumptions made about the price-setting mechanism, namely Calvo vs Rotemberg.

In a nutshell, we find that under Rotemberg framework, disinflation unambiguosly increases inequality, whereas results are ambiguous under Calvo pricing according to whether the CIA channel is at work. As a matter of fact, in the Rotemberg model disinflation causes an increase in the average markup that benefits the asset holders and hinders the RT consumers ${ }^{8}$. In the Calvo model disinflation implies a reduction in the average markup that penalizes Ricardian households. In particular, when the CIA channel is in place, not only it works in the same direction of the markup effect - because disinflation determines lower interest payment to the asset holders - but it also produces a powerful increase of labor income, thereby benefiting non Ricardian households. By the opposite, when the CIA channel is shut off the effect of the increase in per-capita capital takes over and increases inequality, although the markup reduction.

Our analysis also focuses on the welfare implications of disinflations. AR obtain that disinflations unambiguously raise welfare. Differently, in our framework redistributive effects might in fact reduce welfare for one of the two groups. It should also be noted that, due to external habits in the households' utility functions, our analysis accounts for the welfare implications of changes in inequality. We find that in the Calvo model disinflation is welfare improving for

\footnotetext{
${ }^{7}$ The existence of the CIA constraint is controversial. Several contributions in the DSGE literature present models emboding the CIA (see, for instance Christiano, Eichenbaum and Evans, 2005; Schmitt-Grohé and Uribe (2005)) but this is inconsitent with the actual central banks modelling (see, for instance, Christoffel, Coenen and Warne, 2008).

${ }^{8}$ The effects are amplified without CIA.
} 
both household types. However, the larger welfare gain accrues to RT households when the CIA binds while the opposite holds without CIA. In the Rotemberg model, the presence of CIA guarantees a welfare improving disinflation for RT consumers, although the Ricardian households benefit more. Without CIA, disinflation becomes even costly for the liquidity constrained households.

The paper adds to previous contributions on the welfare implications of inflationary regimes which highlight the importance of different portfolio composition of different income groups, where the poor typically hold a relatively large proportion of their wealth in non-interest-bearing assets (Erosa and Ventura, 2002; Albanesi, 2007). Our focus here is clearly different as we investigate the role of two different frictions, that is, price markups and the CIA constraint.

The rest of the paper is organized as follows. The next section describes the main model features in particular focusing on the two price mechanisms. Section 3 focuses on the disinflation experiment and results; section 4 shows some robustness check and section 5 concludes.

\section{The Model}

Our model is an extended version of the NK-DSGE model developed by SchmittGrohé and Uribe (2005), henceforth SGU (2005), and Christiano, Eichenbaum and Evans (2005), henceforth CEE (2005). It embodies both nominal and real frictions. Real frictions include: monopolistic competition in goods and labor markets, external habits in consumption, variable capital utilization and adjustment costs in investment decisions. As for nominal frictions, price and wage stickyness is modelled according to the Calvo and Rotemberg alternative frameworks.

Our model accounts for LAMP, i.e. the economy is populated by two different household types: optimizing (Ricardian) households, who hold assets, and the Rule of Thumb (RT henceforth) households, who consume their current income and do not hold any wealth. Formally, we assume that all households share the same utility function. In particular, their preferences are defined over per capita and total consumption $c_{t}^{i}$ and $c_{t}$ respectively, and per capita labor effort $h_{t}^{i}$ :

$$
U_{t}^{i}=E_{0} \sum_{t=0}^{\infty} \beta^{t}\left\{\ln \left(c_{t}^{i}-b c_{t-1}\right)-\frac{\phi_{1}}{(1+\phi)}\left(h_{t}^{i}\right)^{(1+\phi)}\right\}
$$

where $i=o, r t$ refers to optimizing and RT consumers respectively.

The model features a CIA constraint on the wage bill of firms. This implies that, to pay workers in advance of the production, firms must borrow from financial intermediaries ${ }^{9}$ that, in turn, collect money balances from Ricardian

\footnotetext{
${ }^{9}$ Here we implicitly follow the financial sector characterization adopted in CEE 2005, who assumes that a financial intermediary collects money balances from Ricardian households and from the Central Bank. Such funds are then used to finance the working capital needsof firms, and what is left returns to Ricardian households.
} 
households, . Repayment occurs at the end of each period at the gross nominal interest rate $R_{t}$.

\subsection{Rotemberg (1982) and Calvo (1983)}

Monopolistic competition in good and labor markets respectively entails that firms and unions are price and wage setters, thereby enjoying markets power. The Calvo specification assumes that each period each firm faces a constant probability of being able to reoptimize prices. Therefore monopolistic firms are assumed to have different prices in different periods. A crucial implication of that is a relative-price dispersion leading to a misallocation of resources. In particular, price dispersion appears as an inefficiency loss in aggregate production. As stressed in SGU (2005), the higher is the dispersion, the more labor is needed to produce a given level of output.

The Rotemberg specification produces a symmetric equilibrium in which all firms (unions) reoptimize the same price (wage) at each point in time, bearing a quadratic adjustment cost.

\subsection{Monetary Policy}

We assume that monetary policy follows the non-linear rule:

$$
\frac{R_{t}}{R}=\left(\frac{\pi_{t}}{\pi}\right)^{\phi_{\pi}}
$$

where $R_{t}, R, \pi_{t}, \pi$ respectively denote the current nominal interest rate, interest rate target, current inflation and inflation target. $\phi_{\pi}>1$ is the parameter governing the inflation stabilization.

\subsection{Calibration}

Structural parameter calibration follows CEE $(2005)^{10}$, with two exceptions: the CIA and the indexation degrees parameters. CEE (2005) assumes that the full wage bill is subject to the CIA constraint. Differently, we follow Rabanal (2007) who finds that only $15 \%$ of workers must be paid in advance of the production. Moreover, we depart from CEE (2005) to calibrate the price and wage indexation degrees. As a matter of fact, they simply assume full indexation to past period inflation in order to match the inflation persistence found in the post world war II U.S. data. This is in contrast with a large body of empirical evidence ${ }^{11}$ showing that indexation is at best partial.Therefore, we allow for partial indexation in line with the range of values found in the empirical evidence setting the price indexation at 0.50 and the wage indexation at $0.75^{12}$.

\footnotetext{
${ }^{10}$ Table B1 in Appendix B shows the parameters values with description. Notice that the parameter governing the habit persistence under Rotemberg is calibrated at 0.6 following the literature in the field, rather than 0.65 (as in CEE (2005), to avoid model instability problems.

${ }^{11}$ See, for instance, Sbordone (2006); Smets and Wouters (2007); Benati (2008), (2009); Coogley and Sbordone (2008); Ascari, Castelnuovo, Rossi (2011); Hofman, Peersmann, Straub (2012)

${ }^{12}$ See Smets and Wouters (2003).
} 
We fix the share of Rule of Thumb consumers at $R T=0.3$, according to a conservative parametrisation of LAMP behavior.

Furthemore, in order to compare the two models (Calvo vs Rotemberg), we refer to the paper by Keen and Wang (2007) providing the relationship between the price (wage) adjustment cost parameter and the constant fraction of reoptimizing firms (unions).

\section{The Disinflation Experiment}

The disinflation experiment entails a transition from high- to low-inflation steady state. $^{13}$ In particular, following AR (2012), we assume that the central bank implements a credible cold-turkey disinflation aiming to disinflate the economy from the annual level of $5 \%\left(\pi_{\text {old }}^{*}\right)$ to the target of $2 \%^{14}\left(\pi_{\text {new }}^{*}\right)$. Table 1 reports the steady state percentage variations of output $(y)$, consumption $(c)$, average firms markup $\left(\mu^{p}\right)$, real wage $(w)$, hours $(h)$, capital $(K)$, price $(s)$ and wage $\left(s_{w}\right)$ dispersion under Calvo and price $\left(\xi_{p}\right)$ and wage $\left(\xi_{w}\right)$ quadratic adjustment costs under Rotemberg. In addition to the baseline calibration according to which indexation is partial, the analysis takes also into account the full indexation case where the markup effect vanishes and we can pinpoint the CIA effect.

Table 1 - Steady state percentage variations

\begin{tabular}{l|l|l|l}
\hline \hline Aggregate Variables & \multicolumn{2}{|l}{ Partial Indexation } & Full Indexation \\
\hline & Calvo & Rotemberg & Calvo/Rotemberg \\
$y$ & 0.11 & -0.02 & 0.02 \\
$c$ & 0.08 & 0.07 & 0.02 \\
$\mu^{p}$ & -0.03 & 0.02 & 0 \\
$w$ & 0.28 & 0.17 & 0.20 \\
$h$ & 0.02 & -0.01 & 0.01 \\
$K$ & 0.93 & -0.25 & 0.19 \\
$i$ & 0.02 & -0.01 & 0.01 \\
Price rigidity $\left(s, \xi_{p}\right)$ & -0.04 & -0.03 & 0 \\
Wage rigidity $\left(s_{w}, \xi_{w}\right)$ & -0.05 & -0.04 & 0 \\
\hline \hline
\end{tabular}

Disinflation under Calvo reduces price dispersion that results as an inefficiency loss in aggregate production:

$$
y=\frac{A K^{\alpha} h^{(1-\alpha)}}{s}
$$

\footnotetext{
${ }^{13}$ This explains why the model cannot be analyzed by log-linearizing it around one of the two steady states (see Ascari and Ropele (2012)). For the same reason, Ascari and Merkl (2009) show that the use of log-linear approximation to study disinflation may imply misleading results.

${ }^{14}$ Therefore this experiment takes into account trend inflation values consistent with the post-war history of the industrialized countries.
} 
As a result, output and consumption increase following the rise in capital and hours. Under Rotemberg, the policy comes with an output and employment fall. In fact disinflation reduces the quadratic adjustment costs that appear in the aggregate resource constraint:

$$
y=\frac{c+i+G+\xi_{w} h}{\xi_{p}}
$$

In turn, since investments $(i)$ fall and public spending $(G)$ is held constant, this reduces the wedge between output and consumption. This explains why consumption increases. In fact, the reduction in the fraction of output wasted for adjusting prices and wages more than compensates the decrese in output ${ }^{15}$. Hence, disinflation implies output and consumption to move in opposite directions.

Importantly, the average price markup decreases under Calvo and increases under Rotemberg. To make the point clear, the average markup in the Calvo model reads as:

$$
\mu^{p}=\frac{1}{M C^{r}}=\left[p^{*}\left(\frac{\eta-1}{\eta}\right)\left(\frac{1-\alpha \beta \pi^{\eta(1-\chi)}}{1-\alpha \beta \pi^{(\eta-1)(1-\chi)}}\right)\right]^{-1}
$$

or, in other terms:

$$
\mu^{p}=(1-\alpha) \mu^{*}+\alpha \mu^{\text {old }}
$$

where $\alpha$ is the price stickiness parameter, $\mu^{*}$ and $\mu^{\text {old }}$ respectively denote the markup of optimizing firms and the markup of firms that are not able to reset prices. In particular, $\mu^{*}=\frac{p^{*}}{M C^{r}}=\frac{1}{M C^{r}}\left(\frac{1-\alpha \pi^{(\eta-1)(1-\chi)}}{(1-\alpha)}\right)^{\left(\frac{1}{1-\eta}\right)}$. The increase in the marginal cost is more than compensated for by the reduction of $p^{*}$, therefore $\mu^{*}$ reduces and $\mu^{p}$ as well.

In the Rotemberg model the average markup is defined as:

$$
\mu^{p}=\frac{1}{M C^{r}}=\left[\left(\frac{\eta-1}{\eta}\right)+(1-\beta) \xi_{p}\left(\pi^{(1-\chi)}-1\right) \pi^{(1-\chi)}\right]^{-1}
$$

and it's straighforward to figure out that it increases after the disinflation policy.

Under full indexation the two mechanisms are equivalent. Under Calvo there is no dispersion and under Rotemberg there is no adjustment cost because all prices and wages are indexed to past inflation. Therefore we observe positive variations of the aggregate variables and a constant markup, i.e. $\mu^{p}=\left(\frac{\eta-1}{\eta}\right)$.

Figure 1 shows the transition dynamics ${ }^{16}$ of the macroeconomic variables defined above starting off from the initial annual level of $\pi_{\text {old }}^{*}=5 \%$ achieving the policy target $\pi_{\text {new }}^{*}=2 \%$.

\footnotetext{
${ }^{15}$ See Ascari and Rossi (2012).

${ }^{16}$ The transition paths are expressed in percentage deviations from the first steady state.
} 

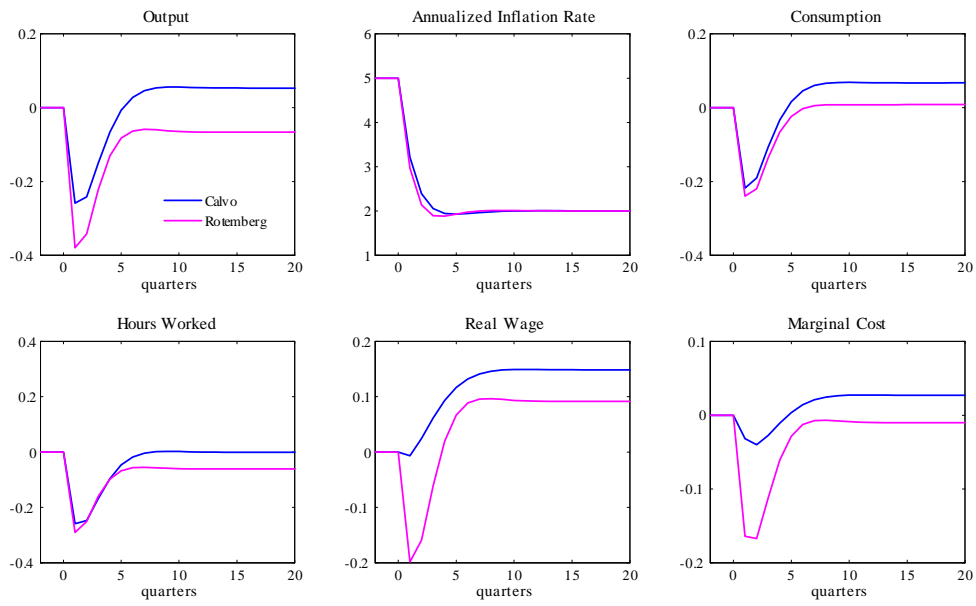

Fig. 1 - Disinflation under Calvo and Rotemberg frameworks

During the transition, disinflation implies a deep recession and a reduction of both consumption and employment under both price mechanisms. It's important to notice the real wage path that under Calvo almost at once jumps to the new and higher steady state. As a matter of fact, in this case the positive long-run effect of the policy takes over the short-run dynamics.

\subsection{Disinflation and Inequality}

In our relatively simple framework, it is possible to obtain an analytical characterization of inequality focusing on the relative consumption and income shares of RT households, $\frac{c^{r t}}{c}$ and $\frac{w h}{y}$ respectively ${ }^{17}$ :

$$
\begin{gathered}
\frac{c^{r t}}{c}=\frac{w h}{y}\left(\frac{c}{y}\right)^{-1}=\left(1-\frac{G}{y}-\frac{i}{y}\right)^{-1}(1-\vartheta)\left\{\mu^{p}\left[1+\nu\left(1-\frac{1}{R}\right)\right]\right\}^{-1} \\
\frac{w h}{y}=(1-\vartheta)\left\{\mu^{p}\left[1+\nu\left(1-\frac{1}{R}\right)\right]\right\}^{-1}
\end{gathered}
$$

where the investment ratio is given by $\frac{i}{y}=\delta\left(\frac{k}{h}\right)^{1-\vartheta}, \frac{G}{y}$ is the public spending ratio and the rental rate of capital is $r^{k}=\frac{1}{\beta}-1+\delta$. Morever $\nu$ denotes the fraction of wage bill that firms must pay in advance of the production and $R$ is the nominal interest rate at which repayment to the asset holders occurs.

From (6) and (7) it is obvious that both $\frac{c^{r t}}{c}$ and $\frac{w h}{y}$ are affected by disinflation through its effects on markups and the CIA constraint. Disinflation reduces the nominal interest rate. Therefore the lower interest rate unambiguously raises the real wage, boosting income and consumption ratios of RT households. A

${ }^{17}$ Derivation of inequality measures is laid out in Appendix C. 
fall in markups would provide similar effects on $\frac{c^{r t}}{c}$ and $\frac{w h}{y}$, but from Table 1 we already know that the Calvo and Rotemberg price setting mechanisms have opposite effects on markups. Table 2 presents numerical computations for our inequality measures.

Table 2 - Inequality measures, steady state percentage variations

\begin{tabular}{l|l|l|l}
\hline \hline Inequality measures & \multicolumn{2}{|l|}{ Partial Indexation } & Full Indexation \\
\hline \multirow{3}{*}{$\frac{c^{r t}}{c}$} & Calvo & Rotemberg & Calvo/Rotemberg \\
$\frac{w h}{y}$ & 0.07 & -0.04 & 0.1 \\
$c^{o}$ & 0.05 & 0.05 & 0.06 \\
$c^{r t}$ & 0.06 & 0.08 & -0.01 \\
\hline \hline
\end{tabular}

Results suggest that disinflation decreases consumption inequality under Calvo and increases it under Rotemberg. In fact Calvo price setting strongly benefits non-Ricardian households and to a much lesser extent favors the asset holders. Under Rotemberg the positive variation of optimizers' consumption is slightly larger than RT's consumption increase. Analysis of the full indexation case, when the markup remains constant, allows to discriminate the different consequences of CIA and markup effects. Lower returns on loans to firms determine a powerful increase of real wages that benefits all households, but Ricardian households loose interest payments from firms. Finally, Calvo and Rotemberg have identical impact on the labor income share although different mechanisms are at work in generating this outcome. In particular, note that $\frac{w h}{y}=\frac{c^{r t}}{c} \frac{c}{y}$. Under Rotemberg the relative consumption of the rule of thumbers $\left(\frac{c^{r t}}{c}\right)$ falls but this is more than compensated for by the increase in the consumption ratio $\left(\frac{c}{y}\right)$. The net effect is a positive variation of $\left(\frac{w h}{y}\right)$ equal to $0.05 \%$. By contrast, under Calvo the increase of $\left(\frac{c^{r t}}{c}\right)$ is accompanied by a modest increase of $\left(\frac{c}{y}\right)$ still determining the same positive variation of $\left(\frac{w h}{y}\right)$.

Figure 2 shows the transition paths of Ricardian and non Ricardian consumption $^{18}$. During the disinflation process, the rule of thumb consumers bear the disinflation costs under both price settings. In fact, while Ricardian consumption achieves the bottom value at -0.20 under Calvo and -0.15 under Rotemberg, non Ricardian consumption achieves the bottom at -0.27 under Calvo and -0.49 under Rotemberg ${ }^{19}$. This is because the rule of thumb consumers cannot smooth consumption and their labor income falls more under Rotemberg.

\footnotetext{
${ }^{18}$ The transition paths are expressed in percentage deviations from the first steady state.

${ }^{19}$ The bottom value is expressed in percentage deviation from the first steady state.
} 

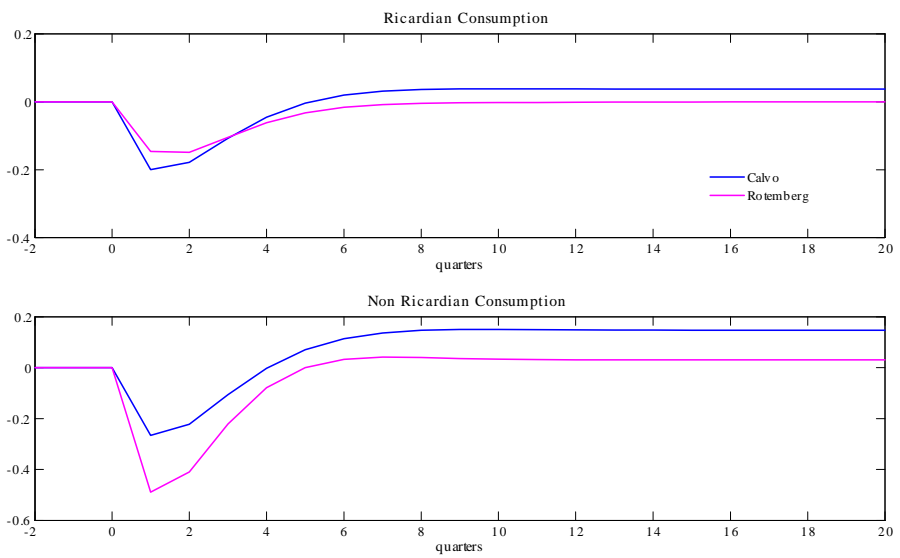

Fig.2 - Ricardian and non Ricardian Consumption

\subsection{Welfare Effects of Disinflation}

We carry out the welfare analysis under the two price- and wage-setting mechanisms. We also analyse the welfare implications of the external habit assumption (catching up with the Jones) by considering the alternative internal habit hypothesis, where concern for relative income disappears. We define $V_{0}^{i}$ and $V_{\text {old }}^{i}$ as the expected values of (1), respectively at time zero (when disinflation experiment is actually implemented) and at the initial steady state (before the disinflation experiment).

Determining $V_{\text {old }}^{i}$ is straighforward:

$$
V_{\text {old }}^{i}=\frac{1}{(1-\beta)}\left[\ln (1-b) c_{\text {old }}^{i}-\frac{\phi_{1}}{(1+\phi)}\left(h_{\text {old }}^{i}\right)^{(1+\phi)}\right] ; i=o, r t
$$

where $c_{\text {old }}^{i}$ and $h_{\text {old }}^{i}$ are respectively the initial steady state values of consumption and hours. Note that $V_{0}^{i}$ accounts for both the new steady state and for the transition phase.

$V_{\text {old }}^{i}$ and $V_{0}^{i}$ allow to compute the welfare-based ratio, $W R^{i}$ :

$$
W R^{i}=-\left(\frac{V_{0}^{i}-V_{\text {old }}^{i}}{\pi_{\text {old }}^{*}-\pi_{\text {new }}^{*}}\right)
$$

where the denominator $\pi_{\text {old }}^{*}-\pi_{\text {new }}^{*}$ allows to weigh the welfare change by the size of disinflation.

Since the utility function is not cardinal, the numerator of the ratio needs to be transformed in a measure which actually can "quantify" the welfare cost (or gain) of disinflation. Following Ascari and Ropele (2012 a, b), the analysis is based on the consumption equivalent measure which is defined as the constant fraction of consumption that households must give up to permanently reduce inflation. The consumption equivalent measure reads as: 


$$
\gamma^{i}=1-\exp \left[(1-\beta)\left(V_{0}^{i}-V_{o l d}^{i}\right)\right]
$$

and the welfare-based ratio is:

$$
W R^{i}=\left(\frac{\gamma^{i}}{\pi_{\text {old }}^{*}-\pi_{\text {new }}^{*}}\right)
$$

Since $\gamma^{i}$ denotes a welfare cost, disinflation is welfare improving when the welfare-based ratio is negative. Therefore, we read the negative values as welfare gains.

Table 3 reports the results.

Table 3 - Welfare Effects

\begin{tabular}{l|l}
\hline Calvo & $W R^{i}$ \\
\hline Ricardian H. & -1.41 \\
Non Ricardian H. & -11.44 \\
\hline Rotemberg & \\
Ricardian H. & -6.63 \\
Non Ricardian H. & -0.42 \\
\hline Full Indexation & \\
Ricardian H. & 3.5 \\
Non Ricardian H. & -9 \\
\hline \hline
\end{tabular}

All the values are expressed in percentage terms

Although disinflation is welfare improving for both household types, the larger welfare gain accrues to RT consumers under Calvo while the opposite occurs under Rotemberg ${ }^{20}$. In fact, the welfare gain is equivalent to only an extra $1.41 \%$ of consumption for Ricardian households and to an extra $11.44 \%$ of consumption for rule of thumbers. However, consistently with the inequality effects, disinflation becomes costly for Ricardian households under the full indexation case where the CIA channel alone benefits RT households and prejudices the asset holders' welfare. In fact, while Ricardian households give up an extra $3.5 \%$ of consumption, liquidity constrained agents gain an extra $9 \%$ of consumption.

\subsection{The Role of the CIA Channel}

In this section we shut off the CIA channel and compute the inequality measures and the welfare effects. ${ }^{21}$ Inequality and welfare results are reported in Table 4 and 5 , respectively.

\footnotetext{
${ }^{20}$ Results hold even under the internal habit specification.

${ }^{21}$ Current DSGE models developed by the central banks do not embody any cash in advance constraint (see, for instance, Christoffel, Coenen and Warne, 2008).
} 
Table 4 - Inequality measures, steady state percentage variations

\begin{tabular}{l|l|l|l}
\hline \hline Inequality measures & \multicolumn{2}{|l|}{ Partial Indexation } & Full Indexation \\
\hline & Calvo & Rotemberg & Calvo/Rotemberg \\
$\frac{c^{r t}}{c}$ & -0.03 & -0.14 & 0 \\
$\frac{w h}{y}$ & -0.001 & -0.001 & 0 \\
$c^{o}$ & 0.13 & 0.09 & 0 \\
$c^{r t}$ & 0.04 & -0.03 & 0 \\
\hline \hline
\end{tabular}

Relative to Table 2, results confirm that under Rotemberg disinflation increases inequality while we reject the conclusion that under Calvo inequality falls. As a matter of fact, when the CIA channel is closed other effects take over, apart from the markup behavior. In particular, in the Calvo model, the lower markup is associated to greater output and to an increase in the stock of capital and in interest payments that entirely accrue to optimizing households.In the Rotemberg model, the markup increase still implies a drop in the consumption of the rule of thumbers and an increase in the asset holders' consumption. However, with respect to the Calvo model, the output fall causes also a drop in the per-capita capital, thereby restraining the Ricardian consumption growth.

\begin{tabular}{l|l} 
Table 5 - Welfare Effects $(\mathbf{C I A}=\mathbf{0})$ \\
\hline Calvo & $W R^{i}$ \\
Ricardian H. & -5.50 \\
Non Ricardian H. & -1.76 \\
\hline Rotemberg & \\
Ricardian H. & -10.79 \\
Non Ricardian H. & 9.12 \\
\hline Full Indexation & \\
Ricardian H. & -0.55 \\
Non Ricardian H. & 0.64 \\
\hline \hline \multicolumn{2}{|l}{ All the values are expressed in percentage terms }
\end{tabular}

Compared to the case with CIA, Table 5 shows that under Calvo the welfare gain of Ricardian households increases while the welfare gain of RT households notably falls. Contrary to the case with CIA, the disinflation policy benefits more the optimizers than the liquidity constrained households. Under Rotemberg, disinflation strongly benefits asset holders and is very costly for nonRicardian households.

\section{Conclusions}

This paper investigates the distributional welfare effects of disinflation in an otherwise standard medium scale DSGE model augmented for LAMP, taking into account the two most commonly used approaches to set prices and wages 
in the New Keynesian literature, i.e. Calvo (1983) staggered price scheme and Rotemberg (1982) price framework.

Results can be summarized as follows. A disinflation policy unambiguosly increases inequality under Rotemberg mechanism. By contrast, under Calvo this effect may obtain only if the CIA constraint doesn't bind firms ability to finance their working capital. 


\section{References}

[1] Albanesi, Stefania, 2007. "Inflation and inequality," Journal of Monetary Economics, Elsevier, vol. 54(4), pages 1088-1114, May.

[2] Ascari, Guido, 2004. "Staggered Prices and Trend Inflation: Some Nuisances," Review of Economic Dynamics, Elsevier for the Society for Economic Dynamics, vol. 7(3), pages 642-667, July.

[3] Ascari, Guido \& Castelnuovo, Efrem \& Rossi, Lorenza, 2011. "Calvo vs. Rotemberg in a trend inflation world: An empirical investigation," Journal of Economic Dynamics and Control, Elsevier, vol. 35(11), pages 1852-1867.

[4] Ascari, Guido \& Merkl, Christian, 2009. "Real Wage Rigidities and the Cost of Disinflations," Journal of Money, Credit and Banking, Blackwell Publishing, vol. 41(2-3), pages 417-435, 03.

[5] Ascari, Guido \& Ropele, Tiziano, 2012. "Disinflation in a DSGE perspective: Sacrifice ratio or welfare gain ratio?," Journal of Economic Dynamics and Control, Elsevier, vol. 36(2), pages 169-182.

[6] Ascari, Guido \& Rossi, Lorenza, 2012. "Trend Inflation and Firms Price-Setting: Rotemberg Versus Calvo," Economic Journal, Royal Economic Society, vol. 122(563), pages 1115-1141, 09.

[7] Ball, Laurence, 1994. "Credible Disinflation with Staggered PriceSetting," American Economic Review, American Economic Association, vol. 84(1), pages 282-89, March.

[8] Benati, Luca, 2008. "Investigating Inflation Persistence Across Monetary Regimes," The Quarterly Journal of Economics, MIT Press, vol. 123(3), pages 1005-1060, August.

[9] Benati, Luca, 2009. "Are 'intrinsic inflation persistence' models structural in the sense of Lucas (1976)?," Working Paper Series 1038, European Central Bank.

[10] Bilbiie, F. O., 2008. "Limited asset markets participation, monetary policy and (inverted) aggregate demand logic," Journal of Economic Theory, Elsevier, vol. 140(1), pages 162-196, May.

[11] Bulír, A., 2001. "Income Inequality: Does Inflation Matter?," IMF Staff Papers, Palgrave Macmillan, vol. 48 (1), pages 5.

[12] Calvo, Guillermo A., 1983. "Staggered prices in a utility-maximizing framework," Journal of Monetary Economics, Elsevier, vol. 12(3), pages 383-398, September. 
[13] Campbell, John Y. \& Mankiw, N. Gregory, 1989. "Consumption, Income and Interest Rates: Reinterpreting the Time Series Evidence," NBER Chapters, in: NBER Macroeconomics Annual 1989, Volume 4, pages 185246 National Bureau of Economic Research, Inc.

[14] Christiano, Lawrence J. \& Eichenbaum, Martin \& Evans, Charles L., 2005. "Nominal Rigidities and the Dynamic Effects of a Shock to Monetary Policy," Journal of Political Economy, University of Chicago Press, vol. 113(1), pages 1-45, February.

[15] Coenen, Günter \& Straub, Roland, 2005. "Does Government Spending Crowd in Private Consumption? Theory and Empirical Evidence for the Euro Area," International Finance, Wiley Blackwell, vol. 8(3), pages 435-470, December.

[16] Cogley, Timothy \& Sbordone, Argia M. 2008. "Trend Inflation, Indexation, and Inflation Persistence in the New Keynesian Phillips Curve," American Economic Review, American Economic Association, vol. 98(5), pages 2101-26, December.

[17] Coibion, Olivier \& Gorodnichenko, Yuriy \& Kueng, Lorenz \& Silvia, John, 2012. "Innocent Bystanders? Monetary Policy and Inequality in the U.S," NBER Working Papers 18170, National Bureau of Economic Research, Inc.

[18] Colciago, Andrea \& Ropele, Tiziano \& Muscatelli, V. Anton \& Tirelli, Patrizio , 2008. "The Role of Fiscal Policy in a Monetary Union: are National Automatic Stabilizers Effective?," Review of International Economics, Wiley Blackwell, vol. 16(3), pages 591-610, 08.

[19] Cooley, Thomas F \& Hansen, Gary D, 1991. "The Welfare Costs of Moderate Inflations," Journal of Money, Credit and Banking, Blackwell Publishing, vol. 23(3), pages 483-503, August.

[20] Cowell F. A., \& Karagiannaki E. \& McKnight, A., 2013. Accounting for cross-country differences in wealth inequality. CASE Papers /168, Centre for Analysis of Social Exclusion, LSE.

[21] Danziger, Leif, 1988. "Costs of Price Adjustment and the Welfare Economics of Inflation and Disinflation," American Economic Review, American Economic Association, vol. 78(4), pages 633-46, September.

[22] Doepke, Matthias \& Schneider, Martin, 2006. "Inflation as a Redistribution Shock: Effects on Aggregates and Welfare," NBER Working Papers 12319, National Bureau of Economic Research, Inc.

[23] Easterly, William \& Fischer, Stanley, 2001. "Inflation and the Poor," Journal of Money, Credit and Banking, Blackwell Publishing, vol. 33(2), pages 160-78, May. 
[24] Erosa, Andres \& Ventura, Gustavo, 2002. "On inflation as a regressive consumption tax," Journal of Monetary Economics, Elsevier, vol. 49(4), pages 761-795, May.

[25] Forni, Lorenzo \& Monteforte, Libero \& Sessa, Luca, 2009. "The general equilibrium effects of fiscal policy: Estimates for the Euro area," Journal of Public Economics, Elsevier, vol. 93(3-4), pages 559-585, April.

[26] Fuhrer, Jeffrey C., 2000. "Habit Formation in Consumption and Its Implications for Monetary-Policy Models," American Economic Review, American Economic Association, vol. 90(3), pages 367-390, June.

[27] Galí, Jordi \& Lopez-Salido, Jose David \& Vallés Liberal, Javier, 2004. "Rule-of-Thumb Consumers and the Design of Interest Rate Rules," CEPR Discussion Papers 4347, C.E.P.R. Discussion Papers.

[28] Galí, Jordi \& Lopez-Salido, Jose David \& Vallés Liberal, Javier, 2007. "Understanding the Effects of Government Spending on Consumption," Journal of the European Economic Association, MIT Press, vol. 5(1), pages 227-270, 03.

[29] Hofmann, Boris \& Peersman, Gert \& Straub, Roland, 2012. "Time variation in U.S. wage dynamics," Journal of Monetary Economics, Elsevier, vol. 59(8), pages 769-783.

[30] Ireland, Peter N., 1995. "Optimal disinflationary paths," Journal of Economic Dynamics and Control, Elsevier, vol. 19(8), pages 1429-1448, November.

[31] Keen, Benjamin \& Wang, Yongsheng, 2007. "What is a realistic value for price adjustment costs in New Keynesian models?," Applied Economics Letters, Taylor and Francis Journals, vol. 14(11), pages 789-793.

[32] Khan, Hashmat, 2005. "Price-setting behaviour, competition, and markup shocks in the new Keynesian model," Economics Letters, Elsevier, vol. 87(3), pages 329-335, June.

[33] Lombardo, Giovanni \& Vestin, David, 2008. "Welfare implications of Calvo vs. Rotemberg-pricing assumptions," Economics Letters, Elsevier, vol. 100(2), pages 275-279, August.

[34] Mankiw, N Gregory, 2001. "The Inexorable and Mysterious Tradeoff between Inflation and Unemployment," Economic Journal, Royal Economic Society, vol. 111(471), pages C45-61, May.

[35] Motta, Giorgio \& Tirelli, Patrizio, 2012. "Optimal Simple Monetary and Fiscal Rules under Limited Asset Market Participation," Journal of Money, Credit and Banking, Blackwell Publishing, vol. 44(7), pages 13511374, October. 
[36] Rabanal, Pau, 2007. "Does inflation increase after a monetary policy tightening? Answers based on an estimated DSGE model," Journal of Economic Dynamics and Control, Elsevier, vol. 31(3), pages 906-937, March.

[37] Roberts John M, 1995. "New Keynesian Economics and the Phillips Curve", Journal of Money, Credit and Banking, Blackwell Publishing, vol. 27(4), pages 975-84, November.

[38] Romer, Christina D. \& Romer, David H., 1998. "Monetary Policy and the Well-Being of the Poor," NBER Working Papers 6793, National Bureau of Economic Research, Inc.

[39] Rotemberg, Julio J, 1982. "Sticky Prices in the United States," Journal of Political Economy, University of Chicago Press, vol. 90(6), pages 11871211, December.

[40] Rotemberg, Julio J, 1987. "The New Keynesian Microfoundations," NBER Chapters, in: NBER Macroeconomics Annual 1987, Volume 2, pages 69-116 National Bureau of Economic Research, Inc.

[41] Sbordone, Argia M. 2006. "U.S. Wage and Price Dynamics: A LimitedInformation Approach," International Journal of Central Banking, International Journal of Central Banking, vol. 2(3), September.

[42] Schmitt-Grohé, Stephanie \& Uribe, Martín, 2005. "Optimal Fiscal and Monetary Policy in a Medium-Scale Macroeconomic Model," NBER Chapters, in: NBER Macroeconomics Annual 2005, Volume 20, pages 383462 National Bureau of Economic Research, Inc.

[43] Smets, Frank \& Wouters, Rafael, 2007. "Shocks and Frictions in US Business Cycles: A Bayesian DSGE Approach," CEPR Discussion Papers 6112, C.E.P.R. Discussion Papers.

[44] Yun, Tack 2005. "Optimal Monetary Policy with Relative Price Distortions," American Economic Review, American Economic Association, vol. 95(1), pages 89-109, March. 


\section{Appendix A: The Model}

In this Appendix we lay out the full model structure.

\subsection{Households}

There is a continuum of households indexed by $i, i \in[0,1] . R T(r t)$ and Ricardian $(o)$ agents are respectively defined over the intervals $[0, \Omega]$ and $[\Omega, 1]$. All households share the same utility function. Each household has preferences defined over consumption $c$ and labour effort $h$. Hence, the period household's utility function is:

$$
U_{t}^{i}=E_{0} \sum_{t=0}^{\infty} \beta^{t}\left\{\ln \left(c_{t}^{i}-b c_{t-1}\right)-\frac{\phi_{1}}{(1+\phi)}\left(h_{t}^{i}\right)^{(1+\phi)}\right\}
$$

where $c_{t}^{i}$ denotes total individual consumption, $b$ represents the degree of external habit formation in consumption, $h_{t}^{i}$ denotes individual labor supply of a differentiated labor bundle. As for preference parameters, $\phi$ is the inverse of the intertemporal elasticity of substitution of labour and $\phi_{1}$ accounts for the relative importance of disutility of work and utility of consumption in the total utility.

\subsection{Consumption bundles}

The consumption good is assumed to be a composite good produced with a continuum of differentiated goods $c_{t}^{i}$ via the Dixit-Stiglitz consumption basket of household $i$ :

$$
c_{t}^{i}=\left[\int_{0}^{1} c(z)_{t}^{\frac{\eta-1}{\eta}} d z\right]^{\frac{\eta}{\eta-1}}
$$

where $\eta>1$ denotes the elasticity of substitution across different varieties of goods.

In particular, the household decides how to allocate its consumption expenditures among different goods. This requires that the consumption index $c_{t}^{i}$ is maximized for any given level of expenditures $X_{t}=\int_{0}^{1} P(z)_{t} c(z)_{t} d z$. Solving the intratemporal goods allocation problem, the set of demand equation is:

$$
c(z)_{t}=\left(\frac{P(z)_{t}}{P_{t}}\right)^{-\eta} c_{t}
$$

where

$$
P_{t}=\left(\int_{0}^{1} p(z)_{t}^{(1-\eta)} d z\right)^{\frac{1}{1-\eta}}
$$

is the aggregate price consumption index. 


\subsection{Labour market structure}

It is assumed a continuum of differentiated labour inputs indexed by $j, j \in$ $[0,1]$. Following Schmitt-Grohé and Uribe (2005), household $i$ supplies all labour inputs. Moreover, labor type-specific unions indexed by $j \in[0,1]$ have some monopoly power in the labour market and make wage-setting decisions. Given the wage $W_{t}^{j}$ fixed by union $j$, households are assumed to supply enough labour $h_{t}^{j}$ to satisfy demand. That is,

$$
h_{t}^{j}=\left(\frac{W_{t}^{j}}{W_{t}}\right)^{-\eta_{w}} h_{t}^{d}
$$

where $\eta_{w}>1$ is the elasticity of substitution across different labour inputs, $h_{t}^{d}$ is the aggregate labour demand and $W_{t}=\left(\int_{0}^{1}\left(W_{t}^{j}\right)^{\left(1-\eta_{w}\right)} d j\right)^{\frac{1}{\left(1-\eta_{w}\right)}}$ is the aggregate wage index. As in Galì (2007), it's assumed that the fraction of Ricardian and non-Ricardian households is uniformly distributed across unions and the aggregate demand for each labor type is uniformly distributed across households. Therefore optimizers and rule of thumbers work for the same amount of work. Therefore the labour supply, which is common across households, must satisfy the resource constraint $h_{t}^{s}=\int_{0}^{1} h_{t}^{j} d j$. Combining the latter with equation (5) we get:

$$
h_{t}^{s}=h_{t}^{d} \int_{0}^{1}\left(\frac{W_{t}^{j}}{W_{t}}\right)^{-\eta_{w}} d j
$$

Therefore, the common labour income is denoted by $h_{t}^{d} \int_{0}^{1}\left(\frac{W_{t}^{j}}{W_{t}}\right)^{-\eta_{w}} d j$.

\subsection{Ricardian Households}

Ricardian agents are assumed to have access to market for physical capital and to contingent nominal assets. In particular, each period asset holders can purchase any state-contingent nominal payment $X_{t+1}$ in period $t+1$ at the cost $E_{t} r_{t, t+1} X_{t+1}$ where $r_{t, t+1}$ is a stochastical discount factor between periods $t$ and $t+1$.

Therefore, the ricardian household's period budget constraint in real terms reads as:

$$
\begin{aligned}
E_{t} r_{t, t+1} x_{t+1}+c_{t}^{o}+i_{t}^{o}= & \frac{x_{t}}{\pi_{t}}+\left[r_{t}^{k} u_{t}-a\left(u_{t}\right)\right] K_{t}^{o}+ \\
& +q_{t} \delta K_{t}^{o}+h_{t}^{d} \int_{0}^{1} w_{t}^{j}\left(\frac{w_{t}^{j}}{w_{t}}\right)^{-\eta_{w}} d j+d_{t}^{o}+d_{t}^{W H}
\end{aligned}
$$

where $\frac{x_{t}}{\pi_{t}} \equiv \frac{X_{t}}{P_{t}}$ is the real payoff in period $t$ of the nominal state contingent assets purchased at $t-1$. $i_{t}^{o}$ denotes the real purchases investment goods at time t. 
It is assumed that ricardian households own physical capital $K_{t}^{o}$, accumulate it and then rent it out the firms at a real interest rate $r_{t}^{k}$. Moreover, the optimizers can control the intensity $u_{t}$ at which the capital is utilized. Hence, the cost of capital depends upon the degree of utilization $a\left(u_{t}\right)$ and it is defined as $a\left(u_{t}\right)=\gamma_{1}\left(u_{t}-1\right)+\frac{\gamma_{2}}{2}\left(u_{t}-1\right)^{2}$. Following CEE (2005) the function satisfies $a(1)=0$ and $a^{\prime}(1), a^{\prime \prime}(1)>0$. Ricardian households also receive firms dividends, $d_{t}^{o}$, and returns from financing working capital of firms ${ }^{22}, d_{t}^{W H}$. The gross rate of inflation is $\pi_{t} \equiv \frac{P_{t}}{P_{t-1}}$.

The capital stock evolves according to the following law of motion:

$$
K_{t+1}^{o}=(1-\delta) K_{t}^{o}+i_{t}^{o}\left[1-S\left(\frac{i_{t}^{o}}{i_{t-1}^{o}}\right)\right]
$$

where $\delta$ is the deprecion rate of capital. The function $S$ introduces the adjustment costs on investment and satisfies the following properties: $S(1)=S^{\prime}(1)=$ $0, S^{\prime \prime}(1)>0$.

Hence, the Lagrangean to the maximization problem, with Lagrange multipliers $\beta^{t} \lambda_{t}\left(1-\tau_{t+s}^{h}\right) w_{t} / \mu_{t}, \beta^{t} \lambda_{t}$ and $\beta^{t} q_{t} \lambda_{t}$ respectively associated to the constraints $(6),(7)$ and $(8)$, reads as:

$L=E_{t} \sum_{s=0}^{\infty}\left\{\begin{array}{c}U\left(c_{t+s}^{o}(i)-b c_{t+s-1}^{o} ; h_{t+s}(i)\right)+ \\ +\lambda_{t+s}^{o}\left[\begin{array}{c}\frac{x_{t+s}}{\pi_{t+s}}+\left[r_{t+s}^{k} u_{t+s}-a\left(u_{t+s}\right)\right] K_{t+s}^{o}+ \\ +q_{t+s} \delta K_{t+s}^{o}+ \\ +h_{t+s}^{d} \int_{0}^{1} w_{t+s}^{j}\left(\frac{w_{t+s}^{j}}{w_{t+s}}\right)^{-\eta_{w}} d j+ \\ +d_{t+s}^{o}-R_{t+s, t+s+1} x_{t+s+1}-c_{t+s}^{o}-i_{t+s}^{o}\end{array}\right]+ \\ +\lambda_{t+s}^{o} q_{t+s}\left[(1-\delta) K_{t+s}^{o}+i_{t+s}^{o}\left[1-S\left(\frac{i_{t+s}^{o}}{i_{t+s-1}^{o}}\right)\right]-K_{t+s+1}^{o}\right]+ \\ +\frac{\lambda_{t+s}^{o}\left(1-\tau_{t+s}^{h}\right) w_{t+s}}{\mu_{t+s}}\left[\begin{array}{c}h_{t+s}^{s}-h_{t+s}^{d} \int_{0}^{1}\left(\frac{w_{t+s}^{j}}{w_{t+s}}\right)^{-\eta_{w}}\end{array}\right]\end{array}\right\}$

The Ricardian household's first order conditions with respect to $c_{t}^{o}, x_{t+1}$, $K_{t}^{o}, i_{t}^{o}$, and $u_{t}$ are respectively:

$$
\begin{gathered}
\frac{1}{c_{t}^{o}-b c_{t-1}}=\lambda_{t}^{o} \\
\lambda_{t}^{o}=\beta R_{t, t+1} \frac{\lambda_{t+1}^{o}}{\pi_{t+1}} \\
q_{t}=\beta \frac{\lambda_{t+1}^{o}}{\lambda_{t}^{o}}\left[q_{t+1}(1-\delta)+r_{t+1}^{k} u_{t+1}-a\left(u_{t+1}\right)\right]
\end{gathered}
$$

\footnotetext{
${ }^{22}$ Here we implicitly follow the financial sector characterization adopted in CEE 2005, who assume that a financial intermediary collects money balances from ricardian households and from the central bank. Such funds are then used to finance the working capital needs of firms, and what is left returns to ricardian huseholds. Given that the Central Bank follows an interest rate policy, explicit modelling of the money market is unnecessary.
} 


$$
\begin{gathered}
\lambda_{t}^{o}=q_{t} \lambda_{t}^{o}\left[1-S\left(\frac{i_{t}^{o}}{i_{t-1}^{o}}\right)-\left[S_{i}\left(\frac{i_{t}^{o}}{i_{t-1}^{o}}\right)\right] i_{t}^{o}\right]+ \\
-\beta q_{t+1} \lambda_{t+1}^{o} S_{i}\left(\frac{i_{t+1}^{o}}{i_{t}^{o}}\right) i_{t+1}^{o} \\
a_{u}\left(u_{t}\right)=r_{t}^{k}
\end{gathered}
$$

Following CEE (2005), the adjustment cost function and the capital utilization function are given by:

$$
\begin{gathered}
S\left(\frac{i_{t}}{i_{t-1}}\right)=\frac{k}{2}\left(\frac{i_{t}}{i_{t-1}}-1\right)^{2} \\
a\left(u_{t}\right)=\gamma_{1}\left(u_{t}-1\right)+\frac{\gamma_{2}}{2}\left(u_{t}-1\right)^{2}
\end{gathered}
$$

\subsection{Rule of thumb households}

As pointed out above, Non-Ricardian agents just consume current labor income because they cannot save neither invest. Since they don't have access to capital markets, they only pay taxes on labor income and receive transfers from the government. Therefore:

$$
c_{t}^{r t}=w_{t} h_{t}^{d}
$$

The marginal utility of consumption for rule of thumbers is:

$$
\frac{1}{c_{t}^{r t}-b c_{t-1}}=\lambda_{t}^{r t}
$$

\subsection{Wage Setting: Calvo framework}

According to the Calvo (1983) framework, each period a union faces a constant probability $\left(1-\alpha_{w}\right)$ of being able to reoptimize wages. In other words, $\alpha_{w}$ denotes the degree of wage stickiness. The unions which are not able to reoptimize the wage index it to past inflation according to the following rule:

$$
W_{t}^{j}=W_{t-1}^{j}\left(\frac{P_{t-1}}{P_{t-2}}\right)^{\chi_{w}}=W_{t-1}^{j} \pi_{t-1}^{\chi_{w}}
$$

where the parameter $\chi_{w} \in[0,1]$ is the indexation parameter.

Unions, in choosing the optimal wage $w_{t}^{*}$, have to take into account that they might not be able to do the same after $s$ periods. If this is the case, taking into account that all unions resetting at time $t$ choose the same wage, the real wage at the generic period $t+s$ will be: 


$$
w_{t+s}=w_{t}^{*} \prod_{k=1}^{s} \frac{\pi_{t+k-1}^{\chi_{w}}}{\pi_{t+k}}
$$

Hence, to derive the households' first order conditions with respect to the optimal wage, it is possible to pull out the part of the Lagrangean which is useful for this purpose. In particular, a weighted average of the two households types utility function is maximized by the optimizing union which will take into account of not being able to reoptimize in the future. Therefore the union objective is:

$$
E_{t} \sum_{s=0}^{\infty}\left(\beta \alpha_{w}\right)^{s}\left\{\begin{array}{c}
\lambda_{t+s}\left[h_{t+s}^{d} w_{t+s}^{\eta_{w}}\left(w_{t}^{*} \prod_{k=1}^{s} \frac{\pi_{t+k-1}^{\chi_{w}}}{\pi_{t+k}}\right)^{\left(1-\eta_{w}\right)}\right]+ \\
-\lambda_{t+s}\left[h_{t+s}^{d} w_{t+s}^{\left(1+\eta_{w}\right)}\left(w_{t}^{*} \prod_{k=1}^{s} \frac{\pi_{t+k-1}^{\chi_{w}}}{\pi_{t+k}}\right)^{\left(-\eta_{w}\right)}\right]
\end{array}\right\}
$$

where, importantly,

$$
\lambda_{t+s}=\left[(1-\Omega) \lambda_{t+s}^{o}+\Omega \lambda_{t+s}^{r t}\right]
$$

is the average marginal utility between the ricardian and non ricardian's marginal utilities.

The first order condition with respect to the optimal wage is:

$$
\begin{gathered}
E_{t} \sum_{s=0}^{\infty}\left(\beta \alpha_{w}\right)^{s} h_{t+s}^{d}\left(\frac{w_{t}^{*}}{w_{t+s}}\right)^{\left(-\eta_{w}\right)}\left(\prod_{k=1}^{s} \frac{\pi_{t+k-1}^{\chi_{w}}}{\pi_{t+k}}\right)^{\left(-\eta_{w}\right)} \lambda_{t+s} \times \\
\times\left\{\begin{array}{c}
\frac{\left(\eta_{w}-1\right)}{\eta_{w}} w_{t}^{*}\left(\prod_{\substack{s=1 \\
k=1}}^{s} \frac{\pi_{t+k-1}^{\chi_{w}}}{\pi_{t+k}}\right)+ \\
+\frac{U_{t+s}}{\lambda_{t+s}}
\end{array}\right\}=0
\end{gathered}
$$

The term $\frac{\left(\eta_{w}-1\right)}{\eta_{w}}$ is the markup which would prevail in absence of wage stickiness $^{23}$.

It's now convenient to write the wage setting equation in recursive form by defining:

$$
\begin{aligned}
f_{1_{t}} \equiv & {\left[\frac{\left(\eta_{w}-1\right)}{\eta_{w}} w_{t}^{*} E_{t} \sum_{s=0}^{\infty}\left(\beta \alpha_{w}\right)^{s} h_{t+s}^{d}\left(\frac{w_{t}^{*}}{w_{t+s}}\right)^{\left(-\eta_{w}\right)}\right.} \\
& \left.\lambda_{t+s}\left(\prod_{k=1}^{s} \frac{\pi_{t+k-1}^{\chi_{w}}}{\pi_{t+k}}\right)^{\left(1-\eta_{w}\right)}\right]
\end{aligned}
$$

\footnotetext{
${ }^{23}$ In the deterministic steady state it also denotes the wage murkup in absence of trend inflation or in case of full indexation, (this is the case in this paper).
} 
and

$$
f_{2_{t}} \equiv-w_{t}^{*\left(-\eta_{w}\right)} E_{t} \sum_{s=0}^{\infty}\left(\beta \alpha_{w}\right)^{s} h_{t+s}^{d} w_{t+s}^{\eta_{w}} U_{n_{t+s}}\left(\prod_{k=1}^{s} \frac{\pi_{t+k-1}^{\chi_{w}}}{\pi_{t+k}}\right)^{\left(-\eta_{w}\right)}
$$

In recursive form:

$$
\begin{aligned}
f_{1_{t}}= & \frac{\left(\eta_{w}-1\right)}{\eta_{w}} w_{t}^{*} h_{t}^{d}\left(\frac{w_{t}}{w_{t}^{*}}\right)^{\left(\eta_{w}\right)} \lambda_{t}+ \\
& +\beta \alpha_{w} E_{t}\left(\frac{w_{t+1}^{*}}{w_{t}^{*}}\right)^{\left(\eta_{w}-1\right)}\left(\frac{\pi_{t}^{\chi_{w}}}{\pi_{t+1}}\right)^{\left(1-\eta_{w}\right)} f_{1_{t+1}}
\end{aligned}
$$

and

$$
f_{2_{t}}=-\left(\frac{w_{t}}{w_{t}^{*}}\right)^{\left(\eta_{w}\right)} h_{t}^{d} U_{n_{t}}+\beta \alpha_{w} E_{t}\left(\frac{w_{t+1}^{*}}{w_{t}^{*}}\right)^{\left(\eta_{w}\right)}\left(\frac{\pi_{t}^{\chi_{w}}}{\pi_{t+1}}\right)^{\left(-\eta_{w}\right)} f_{2_{t+1}}
$$

Hence, the wage setting equation reads as:

$$
f_{1_{t}}=f_{2_{t}}
$$

\subsection{Wage Setting: Rotemberg framework}

In choosing the optimal wage, the unions have to take into account to face a quadratic adjustment cost of the form:

$$
\frac{\xi_{w}}{2}\left(\frac{W_{t}^{j}}{\left(\pi_{t-1}^{\chi_{w}}\right) W_{t-1}^{j}}-1\right)^{2} h_{t}
$$

where $\xi_{w}$ denotes the degree of nominal wage rigidity.

The union objective function in real terms reads as:

$$
\mathcal{L}^{w}=E_{t} \sum_{t=0}^{\infty}\left\{\begin{array}{c}
-\frac{\phi_{1}}{(1+\phi)}\left[h_{t} \int_{0}^{1}\left(\frac{w_{t}^{j}}{w_{t}}\right)^{\left(-\eta_{w}\right)}\right]^{(1+\phi)}+ \\
-\lambda_{t}\left[-\int_{0}^{1}\left(\frac{w_{t}^{j}}{w_{t}}\right)^{\left(1-\eta_{w}\right)} w_{t} h_{t}+\frac{\xi_{w}}{2}\left(\frac{w_{t}^{j}}{w_{t-1}^{j}} \frac{\pi_{t}}{\pi_{t-1}^{*}{ }^{x}}-1\right)^{2} h_{t}\right]
\end{array}\right\}
$$

Since unions choose the same wage, they face the same problem. Therefore a symmetric equilibrium takes place.

From the first order condition the wage setting equation comes out:

$$
m r s_{t}=\left\{\begin{array}{c}
\frac{\eta_{w}-1}{\eta_{w}} w_{t}+\frac{\xi_{w}}{\eta_{w}}\left(\frac{w_{t}}{w_{t-1}} \frac{\pi_{t}}{\pi_{t-1}^{\chi}}-1\right) \frac{w_{t}}{w_{t-1}} \frac{\pi_{t}}{\pi_{t-1}^{\chi w}}+ \\
-\beta \frac{\lambda_{t+1}}{\lambda_{t}} \frac{\xi_{w}}{\eta_{w}}\left(\frac{w_{t+1}}{w_{t}} \frac{\pi_{t+1}}{\pi_{t}^{\chi} w}-1\right) \frac{h_{t+1}}{h_{t}} \frac{w_{t+1}}{w_{t}} \frac{\pi_{t+1}}{\pi_{t}^{\chi x}}
\end{array}\right\}
$$


where, importantly:

$$
\lambda_{t}=\left[(1-\Omega) \lambda_{t}^{o}+\Omega \lambda_{t}^{r t}\right]
$$

\subsection{Firms}

Intermediate firms compete monopolistically by producing good $z$ according to the following technology:

$$
y_{t}(z)=\left(K_{t}(z)\right)^{\vartheta}\left(h_{t}(z)\right)^{(1-\vartheta)}
$$

where $K_{t}(z)$ is the physical capital stock that firms rent by ricardian households and $h_{t}(z)$ is the labor input used by each firm $z$. In particular it is defined as:

$$
h_{t}(z)=\left(\int_{0}^{1}\left(h_{t}^{j}(z)\right)^{\frac{\eta_{w}-1}{\eta_{w}}} d j\right)^{\frac{\eta_{w}}{\eta_{w}-1}}
$$

Firms must pay the wage bill in advance of the production. In other words they are subject to a cash in advance constraint of the form:

$$
m_{z t}^{f}=\nu w_{t} h_{z t}
$$

where $m_{z t}^{f}$ denotes the real money balances by firm $z$ and $\nu$ is the fraction of wage which is payed in advance. The wage is lent by ricardian households which at the end of the period receive back money at the gross nominal interest rate.

Therefore the marginal costs the firms have to face reads as:

$$
m c_{t}=\left(\frac{r_{t}^{k}}{\vartheta}\right)^{\vartheta} w_{t}\left[1+\nu\left(1-\frac{1}{R}\right)\right]
$$

\subsection{Price Setting: Calvo framework}

According to the Calvo (1983) framework, each period a firm faces a constant probability $(1-\alpha)$ of being able to reoptimize prices. In other words, $\alpha$ denotes the degree of price stickiness. The firms which are not able to reoptimize the price index it to past period inflation according to the following rule:

$$
P_{t}(z)=P_{t-1}(z)\left(\frac{P_{t-1}}{P_{t-2}}\right)^{\chi} \pi^{(1-\chi)}=P_{t-1}(z) \pi_{t-1}^{\chi}
$$

where the parameter $\chi \in[0,1]$ is the degree of price indexation.

The firms in choosing the optimal price $P_{t}^{*}$ have to take into account that they might not be able to do the same after $s$ periods. If this is the case, by taking into account that all firms resetting at time $t$ choose the same price, at the generic period $t+s$ it will be:

$$
P_{t, t+s}=P_{t}^{*} \prod_{k=1}^{s} \pi_{t+k-1}^{\chi}
$$


The optimal price $P_{t}^{*}$ is chosen in order to maximize the discounted value of expected future profits. Moreover, it's important to remind here that only ricardian households own firms. Hence, the firms' maximization problem is:

$$
\max _{P_{t}^{*}} E_{t} \sum_{s=0}^{\infty}(\beta \alpha)^{s} \frac{P_{t}}{\lambda_{t}^{o}} \frac{\lambda_{t+s}^{o}}{P_{t+s}}\left(P_{t}^{*} \prod_{k=1}^{s} \pi_{t+k-1}^{\chi}-P_{t+s} m c_{t+s}\right) y_{t, t+s}(z)
$$

subject to:

$$
y_{t, t+s}(z)=\left(\frac{P_{t}^{*} \prod_{k=1}^{s} \pi_{t+k-1}^{\chi}}{P_{t+s}}\right)^{(-\eta)} y_{t+s}^{d}
$$

where $y_{t}^{d}$ is the aggregate demand and $\frac{\lambda_{t+s}^{o}}{\lambda_{t}^{o}}$ denotes the stochastic discount factor of ricardian households.

The first order condition with respect to $P_{t}^{*}$ is:

$E_{t} \sum_{s=0}^{\infty}(\beta \alpha)^{s} \frac{\lambda_{t+s}^{o}}{\lambda_{t}^{o}}\left(\frac{\prod_{k=1}^{s} \pi_{t+k-1}^{\chi}}{\prod_{k=1}^{s} \pi_{t+k}}\right)^{(-\eta)} y_{t+s}^{d}\left(\frac{P_{t}^{*}}{P_{t}}\right)^{(-\eta-1)}\left[\begin{array}{c}\left(\frac{P_{t}^{*}}{P_{t}}\right)\left(\begin{array}{c}\left(\prod_{k=1}^{s} \pi_{t+k-1}^{\chi}\right. \\ \prod_{k=1}^{s} \pi_{t+k}\end{array}\right)+\frac{\eta_{\eta} m c_{t+s}}{(1-\eta)}\end{array}\right]=0$

The term $\frac{(\eta-1)}{\eta}$ is the markup which would prevail in absence of price stickiness $^{24}$.

It's useful to write the price setting equation in recursive form by defining:

$$
x_{1_{t}} \equiv\left(\frac{P_{t}^{*}}{P_{t}}\right)^{(-\eta-1)} E_{t} \sum_{s=0}^{\infty}(\beta \alpha)^{s} \frac{\lambda_{t+s}^{o}}{\lambda_{t}^{o}}\left(\frac{\prod_{k=1}^{s} \pi_{t+k-1}^{\chi}}{\prod_{k=1}^{s} \pi_{t+k}}\right)^{(-\eta)} y_{t+s}^{d} m c_{t+s}
$$

and

$$
x_{2_{t}} \equiv\left(\frac{P_{t}^{*}}{P_{t}}\right)^{(-\eta)} E_{t} \sum_{s=0}^{\infty}(\beta \alpha)^{s} \frac{\lambda_{t+s}^{o}}{\lambda_{t}^{o}}\left(\frac{\prod_{k=1}^{s} \pi_{t+k-1}^{\chi}}{\prod_{k=1}^{s} \pi_{t+k}}\right)^{(1-\eta)} y_{t+s}^{d}
$$

By writing recursively:

\footnotetext{
${ }^{24}$ In the deterministic steady state it also denotes the price murkup in absence of trend inflation or in case of full indexation, (this is the case in this paper).
} 


$$
x_{1_{t}}=p_{t}^{*(-\eta-1)} y_{t}^{d} m c_{t}+E_{t}\left\{(\beta \alpha) \frac{\lambda_{t+1}^{o}}{\lambda_{t}^{o}}\left(\frac{\pi_{t}^{\chi}}{\pi_{t+1}}\right)^{(-\eta)}\left(\frac{p_{t}^{*}}{p_{t+1}^{*}}\right)^{(-\eta-1)} x_{1_{t+1}}\right\}
$$

and

$$
x_{2_{t}}=p_{t}^{*(-\eta)} y_{t}^{d}+E_{t}\left\{(\beta \alpha) \frac{\lambda_{t+1}^{o}}{\lambda_{t}^{o}}\left(\frac{\pi_{t}^{\chi}}{\pi_{t+1}}\right)^{(1-\eta)}\left(\frac{p_{t}^{*}}{p_{t+1}^{*}}\right)^{(-\eta)} x_{2_{t+1}}\right\}
$$

It's possible to rewrite the price setting equation as:

$$
x_{2_{t}}=\frac{\eta}{\eta-1} x_{1_{t}}
$$

\subsection{Price Setting: Rotemberg framework}

The Rotemberg price setting assumes that each intermediate firm pays an increasing and convex cost measured in terms of aggregate output. This cost is given by:

$$
\frac{\xi_{p}}{2}\left(\frac{P_{t}(z)}{\pi_{t-1}^{\chi} P_{t-1}(z)}-1\right)^{2} y_{t}
$$

where $\phi_{p}>0$ measures the degree of nominal price rigidity.

Therefore each firm maximizes its present discounted value of profits for its owners (Ricardian households, i.e. o):

$$
\begin{gathered}
\max _{P_{t}(z)} E_{t}\left[\sum_{s=0}^{\infty} \beta^{s} \lambda_{t+s}^{o} \frac{D_{t+s}(z)}{P_{t+s}}\right] \\
\text { s.t. } y_{t+s}(z)=\left(\frac{P_{t+s}(z)}{P_{t+s}}\right)^{-\eta} y_{t+s}
\end{gathered}
$$

where

$\frac{D_{t+s}(z)}{P_{t+s}}=\frac{P_{t+s}(z)}{P_{t+s}} y_{t+s}(z)-m c_{t+s} y_{t+s}(z)-\frac{\xi_{p}}{2}\left(\frac{P_{t+s}(z)}{\pi_{t+s-1}^{\chi} P_{t+s-1}(z)}-1\right)^{2} y_{t+s}$

Substituting the constraint to the maximization problem into the objective function:

$$
\begin{aligned}
& E_{t} \sum_{s=0}^{\infty} \beta^{s} \lambda_{t+s}^{o}\left[\left(\frac{P_{t+s}(z)}{P_{t+s}}\right)^{1-\eta} y_{t+s}+\right. \\
& \left.-m c_{t+s}\left(\frac{P_{t+s}(z)}{P_{t+s}}\right)^{-\eta} y_{t+s}-\frac{\xi_{p}}{2}\left(\frac{P_{t+s}(z)}{\pi_{t+s-1}^{\chi} P_{t+s-1}(z)}-1\right)^{2} y_{t+s}\right]
\end{aligned}
$$


The FOC to the problem is:

$$
\begin{aligned}
0= & (1-\eta) \lambda_{t}^{o}\left(\frac{P_{t}(z)}{P_{t}}\right)^{-\eta} \frac{y_{t}}{P_{t}}+\eta \lambda_{t}^{o} m c_{t}\left(\frac{P_{t}(z)}{P_{t}}\right)^{-\eta-1} \frac{y_{t}}{P_{t}}+ \\
& -\xi_{p} \lambda_{t}^{o}\left(\frac{P_{t}(z)}{\pi_{t-1}^{\chi} P_{t-1}(z)}-1\right) \frac{y_{t}}{\pi_{t-1}^{\chi} P_{t-1}(z)}+ \\
& +\beta E_{t}\left[\xi_{p} \lambda_{t+1}^{o}\left(\frac{P_{t+1}(z)}{\pi_{t}^{\chi} P_{t}(z)}-1\right) \frac{P_{t+1}(z) y_{t+1}}{\pi_{t}^{\chi} P_{t}(z)^{2}}\right]
\end{aligned}
$$

Given the symmetric equilibrium:

$$
\begin{aligned}
0= & (1-\eta) \lambda_{t}^{o} \frac{y_{t}}{P_{t}}+\eta \lambda_{t}^{o} m c_{t} \frac{y_{t}}{P_{t}}-\phi_{p} \lambda_{t}^{o}\left(\frac{P_{t}}{\pi_{t-1}^{\chi} P_{t-1}}-1\right) \frac{y_{t}}{\pi_{t-1}^{\chi} P_{t-1}}+ \\
& +\beta E_{t}\left[\xi_{p} \lambda_{t+1}^{o}\left(\frac{P_{t+1}}{\pi_{t}^{\chi} P_{t}}-1\right) \frac{P_{t+1} y_{t+1}}{\pi_{t}^{\chi} P_{t}^{2}}\right]
\end{aligned}
$$

Multiplying by $P_{t}$ :

$$
\begin{aligned}
0= & (1-\eta) \lambda_{t}^{o} y_{t}+\eta \lambda_{t}^{o} m c_{t} y_{t}-\xi_{p} \lambda_{t}^{o}\left(\frac{\pi_{t}}{\pi_{t-1}^{\chi}}-1\right) y_{t} \frac{\pi_{t}}{\pi_{t-1}^{\chi}}+ \\
& +\beta E_{t} \xi_{p} \lambda_{t+1}^{o}\left(\frac{\pi_{t+1}}{\pi_{t}^{\chi}}-1\right) \frac{\pi_{t+1}}{\pi_{t}^{\chi}} y_{t+1}
\end{aligned}
$$

Dividing by $y_{t}$ :

$0=(1-\eta) \lambda_{t}^{o}+\eta \lambda_{t}^{o} m c_{t}-\xi_{p} \lambda_{t}^{o}\left(\frac{\pi_{t}}{\pi_{t-1}^{\chi}}-1\right) \frac{\pi_{t}}{\pi_{t-1}^{\chi}}+\beta E_{t} \xi_{p} \lambda_{t+1}^{o}\left(\frac{\pi_{t+1}}{\pi_{t}^{\chi}}-1\right) \frac{\pi_{t+1}}{\pi_{t}^{\chi}} \frac{y_{t+1}}{y_{t}}$

Solving for marginal cost:

$$
m c_{t}=\left(\frac{\eta-1}{\eta}\right)+\frac{\xi_{p}}{\eta}\left(\frac{\pi_{t}}{\pi_{t-1}^{\chi}}-1\right) \frac{\pi_{t}}{\pi_{t-1}^{\chi}}-\beta E_{t} \frac{\xi_{p}}{\eta} \lambda_{t+1}^{o}\left(\frac{\pi_{t+1}}{\pi_{t}^{\chi}}-1\right) \frac{\pi_{t+1}}{\pi_{t}^{\chi}} \frac{y_{t+1}}{y_{t}}
$$

\subsection{Aggregation}

The aggregate production function is:

$$
y_{t}=\left(u_{t} K_{t}\right)^{\vartheta} h_{t}^{d(1-\vartheta)}
$$

and the aggregate absortion is:

$$
y_{t}^{d}=c_{t}+i_{t}+g_{t}+a\left(u_{t}\right) K_{t}
$$

where:

$$
c_{t}=(1-\Omega) c_{t}^{o}+\Omega c_{t}^{r t}
$$




$$
\begin{aligned}
i_{t} & =(1-\Omega) i_{t}^{o} \\
K_{t} & =(1-\Omega) K_{t}^{o}
\end{aligned}
$$

\subsection{Market clearing}

\subsubsection{Goods market equlibrium under Calvo}

The expression warranting the equilibrium in the good market is:

$$
y_{t}=s_{t} y_{t}^{d}
$$

where $s_{t}$ denotes the resource cost due to relative price dispersion in the Calvo model. It evolves according to:

$$
s_{t}=(1-\alpha) p_{t}^{*(-\eta)}+\alpha\left(\frac{\pi_{t}}{\pi_{t-1}^{\chi}}\right)^{\eta} s_{t-1}
$$

where $p_{t}^{*}$, in the light of the aggregate price index, must satisfy:

$$
\alpha \pi_{t}^{(\eta-1)}\left(\pi_{t-1}^{\chi}\right)^{(1-\eta)}+(1-\alpha) p_{t}^{*(1-\eta)}=1
$$

\subsubsection{Goods market equlibrium under Rotemberg}

The aggregate resource constraint accounts for price and nominal wage adjustment costs, therefore:

$$
y_{t}=c_{t}+i_{t}+g_{t}+a\left(u_{t}\right) K_{t}+\frac{\xi_{p}}{2}\left(\frac{\pi_{t}}{\pi_{t-1}^{\chi}}-1\right)^{2} y_{t}+\frac{\xi_{w}}{2}\left(\frac{w_{t}}{w_{t-1}} \frac{\pi_{t}}{\pi_{t-1}^{\chi_{w}}}-1\right)^{2} h_{t}
$$

\subsubsection{Labour market equilibrium under Calvo}

The equilibrium on the labour market is given by:

$$
h_{t}^{s}=\widetilde{s}_{t} h_{t}^{d}
$$

where $\widetilde{s}_{t}$ denotes the resource cost due to relative wage dispersion in the Calvo model. It evolves according to:

$$
\widetilde{s}_{t}=\left(1-\alpha_{w}\right)\left(\frac{w_{t}^{*}}{w_{t}}\right)^{\left(-\eta_{w}\right)}+\alpha_{w}\left(\frac{w_{t-1}}{w_{t}}\right)^{\left(-\eta_{w}\right)}\left(\frac{\pi_{t}}{\pi_{t-1}^{\chi_{w}}}\right)^{\eta_{w}} \widetilde{s}_{t-1}
$$

where it must hold that: 


$$
w_{t}^{*}=\left(\frac{w_{t}^{\left(1-\eta_{w}\right)}-\alpha_{w} w_{t-1}^{\left(1-\eta_{w}\right)}\left(\frac{\pi_{t-1}^{\chi_{w}}}{\pi_{t}}\right)^{\left(1-\eta_{w}\right)}}{\left(1-\alpha_{w}\right)}\right)^{\frac{1}{\left(1-\eta_{w}\right)}}
$$

\subsection{Fiscal Authority}

Public spending is financed through seigniorage:

$$
g_{t}=m_{t}-\frac{m_{t-1}}{\pi_{t}}
$$

where $m_{t}$ denotes real money balances and $\pi_{t}$ is the actual gross inflation rate. Government minimizes the costs of purchasing the composite good. Therefore, government's absorption of a single type of good is $g_{z t}=\left(\frac{P_{z t}}{P_{t}}\right)^{-\eta} g_{t}$.

\subsection{Monetary Authority}

Monetary authority sets the nominal interest rate according to the non-linear rule described above:

$$
\frac{R_{t}}{R}=\left(\frac{\pi_{t}}{\pi}\right)^{\phi_{\pi}}
$$




\section{Appendix B: Calibration}

Baseline calibration of the structural parameter values follows CEE (2005).

$\begin{array}{lll}\begin{array}{l}\text { Table B1: } \\ \text { Parameter }\end{array} & \text { Palue } & \text { Description } \\ \begin{array}{l}\text { Households } \\ \beta\end{array} & 1.03^{(-1 / 4)} & \text { Subjective discount factor } \\ b & 0.65 & \begin{array}{l}\text { Degree of habit persistence } \\ \phi\end{array} \\ \phi_{1} & 1 & \text { Inverse of intertemporal substitution of labor } \\ \eta_{w} & 21 & \text { Disutility of work } \\ \Omega & 0.30 & \text { Wage elasticity of demand for a specific labor variety } \\ \alpha_{w} & 0.64 & \text { Calvo of Ruge of Thumb consumers } \\ \chi_{w} & 0.75^{*} & \text { Wage indexation } \\ \text { Firms } & & \\ \vartheta & 0.36 & \text { Share of capital in value added } \\ \delta & 0.025 & \text { Depreciation rate of capital } \\ \eta & 6 & \text { Price elasticity of demand for a specific good variety } \\ \alpha & 0.6 & \text { Calvo price } \\ \chi & 0.50^{*} & \text { Price indexation } \\ \nu & 0.15^{*} & \text { Cash in advance parameter } \\ \text { Monetary } & \text { Authority } & \\ \phi_{\pi} & 1.5 & \text { Inflation stabilization }\end{array}$




\section{Appendix C: Steady State Solution and In- equality Measures}

\subsection{Steady State in Calvo}

From the wage setting equations A10 and A11 we get:

$$
f_{1}=\left(\frac{\eta_{w}-1}{\eta_{w}}\right)\left(\frac{w^{*} h A M U}{1-\alpha_{w} \beta \pi^{\left(\eta_{w}-1\right)\left(1-\chi_{w}\right)}}\right)\left(\frac{w}{w^{*}}\right)^{\eta_{w}}
$$

and

$$
f_{2}=-\left(\frac{A M D h}{1-\alpha_{w} \beta \pi^{\eta_{w}}\left(1-\chi_{w}\right)}\right)\left(\frac{w}{w^{*}}\right)^{\eta_{w}}
$$

where the Average Marginal Utility is $A M U=(1-R T) \lambda^{o}+R T \lambda^{r t}$ and $\lambda^{o}=$ $\frac{1}{c^{o}-b c}$ and $\lambda^{r t}=\frac{1}{c^{r t}-b c}$. Therefore:

$$
A M U=\frac{1-R T}{c^{o}-b c}+\frac{R T}{c^{r t}-b c}
$$

The Average Marginal Disutility is:

$$
A M D=-\phi_{1} \widetilde{s} h
$$

In equilibrium A12 holds. Imposing equality between $\mathrm{C} 1$ and $\mathrm{C} 2$ we get:

$$
\frac{\phi_{1} \tilde{s} h}{1-\alpha_{w} \beta \pi^{\eta_{w}\left(1-\chi_{w}\right)}}=\left(\frac{\eta_{w}-1}{\eta_{w}}\right)\left[\frac{w^{*}\left(\frac{1-R T}{c^{o}-b c}+\frac{R T}{c^{r t}-b c}\right)}{1-\alpha_{w} \beta \pi^{\left(\eta_{w}-1\right)\left(1-\chi_{w}\right)}}\right]
$$

Notice that:

$$
c^{r t}=w h
$$

Therefore:

$$
\frac{\phi_{1} \widetilde{s} h}{1-\alpha_{w} \beta \pi^{\eta_{w}\left(1-\chi_{w}\right)}}=\left(\frac{\eta_{w}-1}{\eta_{w}}\right)\left[\frac{w^{*}\left(\frac{1-R T}{c^{o}-b c}+\frac{R T}{w h-b c}\right)}{1-\alpha_{w} \beta \pi^{\left(\eta_{w}-1\right)\left(1-\chi_{w}\right)}}\right]
$$

Dividing by $\left(\frac{\eta_{w}-1}{\eta_{w}}\right) w^{*}$ and multiplying by $1-\alpha_{w} \beta \pi^{\eta_{w}\left(1-\chi_{w}\right)}$ :

$$
\frac{\phi_{1} \widetilde{s} h}{\left(\frac{\eta_{w}-1}{\eta_{w}}\right) w^{*}}=\left(\frac{1-R T}{c^{o}-b c}+\frac{R T}{w h-b c}\right)\left(\frac{1-\alpha_{w} \beta \pi^{\eta_{w}}\left(1-\chi_{w}\right)}{1-\alpha_{w} \beta \pi^{\left(\eta_{w}-1\right)\left(1-\chi_{w}\right)}}\right)
$$

Defining: $\Gamma_{1} \equiv\left(\frac{\eta_{w}-1}{\eta_{w}}\right) w^{*}$ and $\Gamma \equiv\left(\frac{1-\alpha_{w} \beta \pi^{\eta_{w}\left(1-\chi_{w}\right)}}{1-\alpha_{w} \beta \pi^{\left(\eta_{w}-1\right)\left(1-\chi_{w}\right)}}\right)$, we rewrite:

$$
\frac{\phi_{1} \tilde{s} h}{\Gamma_{1}}=\left(\frac{1-R T}{c^{o}-b c}+\frac{R T}{w h-b c}\right) \Gamma
$$


Defining $A 1 \equiv\left(\frac{k}{h}\right)$, the average consumption $c=\frac{c}{y} y$, where $y=k^{\vartheta} h^{(1-\vartheta)}=$ $\left(\frac{k}{h}\right)^{\vartheta} h=A 1^{\vartheta} h$ and $\frac{c}{y}=1-\frac{G}{y}-\frac{I}{y}=1-g-\frac{\delta k}{A 1^{\vartheta} h}=1-g-\delta A 1^{(1-\vartheta)}$, reads as:

$$
c=A 1^{\vartheta} h\left(1-g-\delta A 1^{(1-\vartheta)}\right)
$$

Rewriting C6 and defining $\Gamma_{3} \equiv 1-g-\delta A 1^{(1-\vartheta)}$ :

$$
\frac{\phi_{1} \widetilde{s} h}{\Gamma_{1}}=\left(\frac{1-R T}{c^{o}-b\left(A 1^{\vartheta} h \Gamma_{3}\right)}+\frac{R T}{w h-b\left(A 1^{\vartheta} h \Gamma_{3}\right)}\right) \Gamma
$$

Rearranging terms, we can get now an equation for $c^{o}$ as a function of $h$ :

$$
c^{o}=\frac{(1-R T)+b A 1^{\vartheta} h \Gamma_{3}\left(\frac{\phi_{1} \widetilde{s} h}{\Gamma \Gamma_{1}}-\frac{R T}{w h-b A 1^{\vartheta} h \Gamma_{3}}\right)}{\left(\frac{\phi_{1} \widetilde{s} h}{\Gamma \Gamma_{1}}-\frac{R T}{w h-b A 1^{\vartheta} h \Gamma_{3}}\right)}
$$

Recall that the aggregate resource constraint reads as:

$$
A 1^{\vartheta} h=s[c+I+G+a(u) k]
$$

From the aggregate resource constraint it's now possible to obtain steady state hours, knowing that:

$$
\begin{aligned}
c & =(1-R T) c^{o}+R T c^{r t} \\
I & =\delta k=\delta \frac{k}{h} h=\delta A 1 h \\
a(u) & =0
\end{aligned}
$$

Therefore, rewrite C9 taking into account C10, C8, C5 and C11:

$$
A 1^{\vartheta} h=s\left\{(1-R T)\left[\begin{array}{c}
\left.\frac{(1-R T)+b A 1^{\vartheta} h \Gamma_{3}\left(\frac{\phi_{1} \tilde{s} h}{\Gamma \Gamma_{1}}-\frac{R T}{w h-b A 1^{\vartheta} h \Gamma_{3}}\right)}{\left(\frac{\phi_{1} \tilde{s} h}{\Gamma \Gamma_{1}}-\frac{R T}{w h-b A 1^{\vartheta} h \Gamma_{3}}\right)}\right]+ \\
+R T w h+\delta A 1 h+G
\end{array}\right\}\right.
$$

In rearranging and collecting terms, rewrite $\frac{s \phi_{1} h G}{\Gamma \Gamma_{1}}$ as $\frac{s \phi_{1} \widetilde{s} h^{2} g A 1^{\vartheta}}{\Gamma \Gamma_{1}}$ and $\frac{s R T G}{w h-b A 1^{\vartheta} h \Gamma_{3}}$ as $\frac{s R T g A 1^{\vartheta}}{w-b A 1^{\vartheta} h \Gamma_{3}}$, having defined $g \equiv \frac{G}{y}$.

Therefore:

$$
h=\left(\frac{\Gamma_{7}}{\Gamma_{6}}\right)^{\frac{1}{2}}
$$

where:

$$
\begin{gathered}
\Gamma_{7} \equiv s(1-R T)^{2}+\frac{A 1^{\vartheta} R T}{\Gamma_{4}}-\frac{s(1-R T) b A 1^{\vartheta} \Gamma_{3} R T}{\Gamma_{4}}-\frac{s R T g A 1^{\vartheta}}{\Gamma_{4}}-\frac{s R T \Gamma_{5}}{\Gamma_{4}} \\
\Gamma_{6} \equiv \frac{A 1^{\vartheta} \phi_{1} \widetilde{s}}{\Gamma \Gamma_{1}}-\frac{s(1-R T) b A 1^{\vartheta} \Gamma_{3} \phi_{1} \widetilde{s}}{\Gamma \Gamma_{1}}-\frac{s \phi_{1} \widetilde{s} g A 1^{\vartheta}}{\Gamma \Gamma_{1}}-\frac{s \phi_{1} \widetilde{s} \Gamma_{5}}{\Gamma \Gamma_{1}} \\
\Gamma_{5} \equiv R T w+\delta A 1 \\
\Gamma_{4} \equiv w-b A 1^{\vartheta} \Gamma_{3}
\end{gathered}
$$




\subsection{Steady State in Rotemberg}

The marginal rate of substitution in steady state is:

$$
\frac{\phi_{1} h^{\phi}}{A M U}=\left(\frac{\eta_{w}-1}{\eta_{w}}\right) w+\frac{(1-\beta)}{\eta_{w}} \xi_{w}\left(\pi^{\left(1-\chi_{w}\right)}-1\right) \pi^{\left(1-\chi_{w}\right)}
$$

Recalling C3 and rearranging terms, we rewrite C13 as:

$$
\phi_{1} h^{\phi}=\left(\frac{1-R T}{c^{o}-b c}+\frac{R T}{c^{r t}-b c}\right) \Omega
$$

where $\Omega \equiv\left(\frac{\eta_{w}-1}{\eta_{w}}\right) w+\frac{(1-\beta)}{\eta_{w}} \xi_{w}\left(\pi^{\left(1-\chi_{w}\right)}-1\right) \pi^{\left(1-\chi_{w}\right)}$.

Recalling C5 and C7, we rewrite:

$$
\phi_{1} h^{\phi}=\left[\frac{1-R T}{c^{o}-b\left(A 1^{\vartheta} h \Gamma_{3}\right)}+\frac{R T}{w h-b\left(A 1^{\vartheta} h \Gamma_{3}\right)}\right] \Omega
$$

Rearranging terms, we can get now an equation for $c^{o}$ as a function of $h$ :

$$
c^{o}=\frac{(1-R T)+b A 1^{\vartheta} h \Gamma_{3}\left(\frac{\phi_{1} h^{\phi}}{\Omega}-\frac{R T}{w h-b\left(A 1^{\vartheta} h \Gamma_{3}\right)}\right)}{\left(\frac{\phi_{1} h^{\phi}}{\Omega}-\frac{R T}{w h-b\left(A 1^{\vartheta} h \Gamma_{3}\right)}\right)}
$$

Recall that the aggregate resource constraint reads as:

$$
y=c+I+G+a(u) k+\frac{\xi_{p}}{2}\left(\pi^{(1-\chi)}-1\right)^{2} y+\frac{\xi_{w}}{2}\left(\pi^{\left(1-\chi_{w}\right)}-1\right)^{2} h
$$

Recalling that:

$$
\begin{aligned}
y & =A 1^{\vartheta} h \\
c & =(1-R T) c^{o}+R T c^{r t} \\
I & =\delta A 1 h \\
a(u) & =0 \\
\phi & =1
\end{aligned}
$$

Rewrite C15:

$$
\begin{aligned}
A 1^{\vartheta} h Z_{1}= & (1-R T)\left[\frac{(1-R T)+b A 1^{\vartheta} h \Gamma_{3}\left(\frac{\phi_{1} h}{\Omega}-\frac{R T}{w h-b\left(A 1^{\vartheta} h \Gamma_{3}\right)}\right)}{\left(\frac{\phi_{1} h}{\Omega}-\frac{R T}{w h-b\left(A 1^{\vartheta} h \Gamma_{3}\right)}\right)}\right]+ \\
& +R T w h+\delta A 1 h+G+Z Z h
\end{aligned}
$$

where: $Z_{1} \equiv(1-Z) ; Z \equiv \frac{\xi_{p}}{2}\left(\pi^{(1-\chi)}-1\right)^{2}$ and $Z Z \equiv \frac{\xi_{w}}{2}\left(\pi^{\left(1-\chi_{w}\right)}-1\right)^{2}$.

In rearranging and collecting terms, rewrite $\frac{\phi_{1} h G}{\Omega}$ as $\frac{\phi_{1} h^{2} g A 1^{\vartheta}}{\Omega}$ and $\frac{R T G}{w h-b\left(A 1^{\vartheta} h \Gamma_{3}\right)}$ as $\frac{R T g A 1^{\vartheta}}{w-b\left(A 1^{\vartheta} \Gamma_{3}\right)}$. 
Therefore:

$$
h=\left(\frac{Z_{5}}{Z_{6}}\right)^{\frac{1}{2}}
$$

where:

$$
\begin{aligned}
Z_{5} \equiv & \frac{A 1^{\vartheta} Z_{1} R T}{\Gamma_{4}}+(1-R T)^{2}-\frac{(1-R T) R T b A 1^{\vartheta} \Gamma_{3}}{\Gamma_{4}}-\frac{R T^{2} w}{\Gamma_{4}}-\frac{R T \delta A 1}{\Gamma_{4}}+ \\
& -\frac{R T g A 1^{\vartheta}}{\Gamma_{4}}-\frac{R T Z Z}{\Gamma_{4}} \\
Z_{6} \equiv & \frac{A 1^{\vartheta} Z_{1} \phi_{1}}{\Omega}-\frac{(1-R T) b A 1^{\vartheta} \Gamma_{3} \phi_{1}}{\Omega}-\frac{\phi_{1} R T w}{\Omega}-\frac{\phi_{1} \delta A 1}{\Omega}-\frac{\phi_{1} g A 1^{\vartheta}}{\Omega}-\frac{\phi_{1} Z Z}{\Omega}
\end{aligned}
$$

\subsection{Inequality Measures}

In this Appendix we derive the following inequality measures: $\frac{c^{r t}}{c}$ and $\frac{w h}{y}$ under the Calvo price mechanism.

The relative consumption of rule of thumbers can be written as:

$$
\frac{c^{r t}}{c}=\frac{w h}{y}\left(\frac{c}{y}\right)^{-1}=\left(1-\frac{G}{y}-\frac{I}{y}\right)^{-1} w\left(\frac{h}{k}\right)^{\vartheta}
$$

From the cost minimization problem the marginal cost reads as:

$$
M C=\left(\frac{r^{k}}{\vartheta}\right)^{\vartheta}\left[\frac{w\left[1+\nu\left(1-\frac{1}{R}\right)\right]}{(1-\vartheta)}\right]^{(1-\vartheta)}
$$

Recalling also that the average markup is defined as:

$$
\mu^{p}=\frac{1}{M C}
$$

the real wage is:

$$
w=(1-\vartheta)\left(\frac{k}{h}\right)^{\vartheta}\left\{\mu^{p}\left[1+\nu\left(1-\frac{1}{R}\right)\right]\right\}^{-1}
$$

Therefore:

$$
\frac{c^{r t}}{c}=\frac{w h}{y}\left(\frac{c}{y}\right)^{-1}=\left(1-\frac{G}{y}-\frac{I}{y}\right)^{-1}(1-\vartheta)\left\{\mu^{p}\left[1+\nu\left(1-\frac{1}{R}\right)\right]\right\}^{-1}
$$

where $\frac{I}{y}=\delta\left(\frac{k}{h}\right)^{1-\vartheta}$ and $\frac{k}{h}=\left(\frac{r^{k}}{\vartheta M C}\right)^{\left(\frac{1}{(\vartheta-1)}\right)}$.

It's now straightforward to obtain:

$$
\frac{w h}{y}=(1-\vartheta)\left\{\mu^{p}\left[1+\nu\left(1-\frac{1}{R}\right)\right]\right\}^{-1}
$$

